\title{
Criptografia e Segurança Web: um relato de experiência do ensino de conceitos computacionais para crianças.
}

\author{
Guilherme Carvalho Rodrigues, Rafael Debastiani do Carmo Braga, Thiago \\ Batista Amorim
}

\author{
Instituto Federal de Brasília - Campus Taguatinga (IFB) \\ Distrito Federal - DF - Brasil \\ guilherme.carvalhor@hotmail.com, rafaeldcb@gmail.com, \\ thiago.amorimeifb.edu.br
}

\begin{abstract}
This meta-article deals with the teaching experience of children from two elementary schools of the Federal District in the year 2018, based on the discipline of Practices II. In order to develop computational skills. Two courses were offered: WEB Security and Cryptography. Having as methodologies the Plugged and Unplugged Computing. The results allow us to affirm that the use of different strategies to explain the contents allowed the students to develop more in the learning process.
\end{abstract}

Resumo. Este artigo trata sobre a experiência de ensino de computação para crianças de duas escolas de ensino fundamental do Distrito Federal no ano de 2018, realizados a partir da disciplina de Práticas II. Com o objetivo de desenvolver habilidades computacionais. Foram ofertados dois cursos: Segurança WEB e Criptografia. Tendo como metodologias a Computação Plugada e Desplugada. Os resultados permitem afirmar que o uso de diferentes estratégias para explicação dos conteúdos permitiram o desenvolvimento maior dos alunos no processo de aprendizado.

\section{Introdução}

Se faz cada vez mais necessária a introdução do ensino de conceitos computacionais nas escolas, sendo esta de extrema importância no contexto ao qual estamos inseridos de comunicação e em meio às mídias digitais. Nascidos e imersos em meio as tecnologias as crianças e adolescentes cada vez mais cedo tem entrado em contato com o mundo digital. Segundo (CASTRO; VILLARIM, 2013) a sociedade do século XXI vive profundas e velozes transformações sociais e tecnológicas. Vive-se a informatização em diversos contextos, nas empresas e nos lares; está estabelecida a consolidação da cultura digital; e as redes sociais e a virtualidade computacional estão presentes no cotidiano.

Mas, afinal qual o papel do professor de computação frente a essa problemática? O mesmo deverá prepará-las e ajudá-las no seu desenvolvimento dentro dos meios digitais. Nesse momento de preparação se faz necessário um pensamento crítico por parte do professor para que este possa levar as crianças a questionamentos. É fato que não basta apenas saber manipular aplicativos, as crianças devem ser capazes de possuir uma criticidade frente às tecnologias, o mundo digital e a cultura digital. 
A finalidade do projeto foi empregar métodos de ensino-aprendizagem que introduzem conceitos computacionais por meio de oficinas ofertadas a estudantes de ensino fundamental, sendo dois cursos ofertados, intitulados: i) Segurança Web; ii) Criptografia. Foram utilizadas duas estratégias para o desenvolvimento das oficinas: Para a de Segurança: Computação Plugada e para Criptografia foi Computação Desplugada. Sobre computação desplugada, Bordini et al (2016) esclarecem que é uma estratégia que visa a ensinar os fundamentos da computação de forma lúdica, sem o uso de computadores, podendo ser aplicada para pessoas de todas as idades, desde o ensino fundamental até o ensino superior, com diferentes conhecimentos e experiências.

\section{Metodologia}

Este trabalho foi desenvolvido a partir das experiências realizadas em sala de aula com crianças de duas escolas de Ceilândia e Taguatinga, cidades satélites de Brasília no Distrito Federal, uma pública e outra particular. O trabalho foi organizado em três etapas descritas abaixo.

$\mathrm{Na}$ primeira etapa foram dedicados cerca de dois meses para leitura de artigos e elaboração dos planos de aula e ensino com a definição dos temas que iriam permear os trabalhos. Na segunda etapa elaborou-se os materiais pedagógicos plugados e desplugados. Na terceira etapa, como parte fundamental para o andamento das propostas, foram aplicadas as oficinas com estes estudantes ocorrendo em oito encontros presenciais, quatro para cada escola participante, com duração de quatro horas por encontro.

As oficinas adotaram práticas inovadoras relacionadas à inserção de novas tecnologias no ambiente da sala de aula e ao trabalho pedagógico. A seguir são apresentadas informações detalhadas sobre estas.

\subsection{Oficinas Criptografía}

As oficinas de criptografia foram aplicadas com quatro turmas, sendo duas oriundas de escola pública e duas da escola particular. Os conteúdos das disciplinas foram divididos da seguinte forma: i) Introdução a Criptografia - Histórico; ii) Cifra de César; iii) Criptografia na atualidade.

Houve uma preocupação em desenvolver os conteúdos que seriam empregados em sala de aula de uma forma simples e com uma linguagem de fácil assimilação pelos alunos. É importante ressaltar que os conteúdos foram desenvolvidos a partir de histórias animadas, levando exemplos do dia-a-dia como aplicativos de mensagens instantâneas, jogos online.

Nesta perspectiva no primeiro momento das aulas foram realizadas avaliações diagnósticas com os estudantes para verificar o contexto ao qual estão inseridos e suas vivências frente às tecnologias. Em seguida foi apresentado a criptografia, suas aplicações e o exemplo da cifra de césar. Buscando apropriação do conteúdo foram realizadas algumas atividades práticas no formato individual e coletivo, que são descritas na Tabela 1. 
VIII Congresso Brasileiro de Informática na Educação (CBIE 2019)

Anais do XXV Workshop de Informática na Escola (WIE 2019)

Tabela 1 - Atividades trabalhadas em sala de aula no curso de Criptografia

\begin{tabular}{|c|l|c|}
\hline Atividade & \multicolumn{1}{|c|}{ Descrição } & Formato \\
\hline $\begin{array}{c}\text { Pequena Cifra } \\
\text { de César }\end{array}$ & $\begin{array}{l}\text { Expor no quadro uma frase criptografada em cifra de César para } \\
\text { ser descriptografada. }\end{array}$ & Individual \\
\hline $\begin{array}{c}\text { Descubra a } \\
\text { cifra correta }\end{array}$ & $\begin{array}{l}\text { No data-show ficará três frases criptografadas em três diferentes } \\
\text { cifras, ROT13, Cifra de César e ROT7, onde os alunos deverão } \\
\text { descobrir qual texto está cifrado em suas respectivas cifras e } \\
\text { realizar as decriptografia. }\end{array}$ & Individual \\
\hline $\begin{array}{c}\text { Montando sua } \\
\text { própria Cifra }\end{array}$ & $\begin{array}{l}\text { Os participantes recebem uma folha quadriculada contendo } \\
\text { todas as letras do alfabeto para criarem sua própria cifra por } \\
\text { meio de símbolos disponíveis em outra folha, com a finalidade } \\
\text { de criptografar uma mensagem. }\end{array}$ & Individual \\
\hline $\begin{array}{c}\text { Vamos } \\
\text { Decriptar }\end{array}$ & $\begin{array}{l}\text { Cada equipe receberá uma folha com a chave, na lousa haverá } \\
\text { uma frase criptografada e eles deverão descriptografar. Vence a } \\
\text { equipe que conseguir descriptografar primeiro a mensagem. }\end{array}$ & Equipe \\
\hline $\begin{array}{c}\text { Licurgo / Caça } \\
\text { ao Tesouro }\end{array}$ & $\begin{array}{l}\text { Cada equipe deverá encontrar 3 bastões de Licurgo escondidos } \\
\text { pela sala de aula. Em uma mesa haverão fitas compridas que em } \\
\text { conjunto com o bastão decifra a mensagem na fita. Os } \\
\text { participantes deverão encontrar a posição correta da fita no } \\
\text { bastão e decifrar encontrando a mensagem codificada, que dá a } \\
\text { dica de onde se encontra o próximo bastão. Vence a equipe que } \\
\text { conseguir decifrar todos os 3 bastões primeiro. }\end{array}$ & Equipe \\
\hline EMOJIS & $\begin{array}{l}\text { Cada equipe escolhe uma frase para ser decriptada, a ferramenta } \\
\text { utilizada será o Codemoji (https://codemoji.org), que seráa } \\
\text { emojis utilizados na criptografia por meio de dicas. }\end{array}$ & Equipe \\
\hline
\end{tabular}

Optou-se por organizar as cadeiras em um formato de semicírculo para facilitar a comunicação entre as crianças e por sua vez ajudar no desenvolvimento das atividades, que ora eram individuais e outras vezes em grupo como mostra a Figura 1.

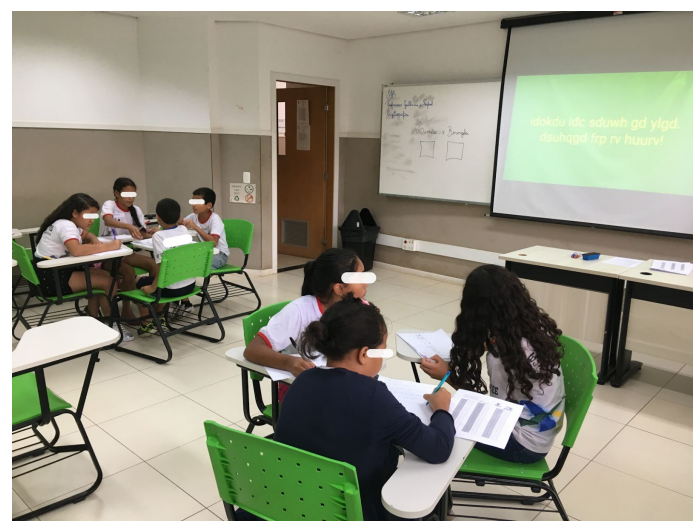

Figura 1. Crianças em equipe realizando atividade de Criptografia 
VIII Congresso Brasileiro de Informática na Educação (CBIE 2019)

Anais do XXV Workshop de Informática na Escola (WIE 2019)

\subsection{Oficinas Segurança Web}

As oficinas de segurança web foram aplicadas com quatro turmas. As atividades foram realizadas dentro do laboratório de informática e cada aluno possuía um computador. Os conteúdos abordados na oficina foram divididos da seguinte forma: i) Introdução a segurança na Web; ii) Compartilhe com Cuidado; iii) Não caia em armadilhas; iv) Proteja seus segredos; v) É legal ser gentil; vi) Na dúvida não fale com ninguém.

Os conteúdos foram baseados em uma plataforma online denominada "Interland", criado pela Google para disseminação de boas práticas na internet através de jogos educativos. Buscou-se sempre fazer uma contextualização dos conteúdos para preparar os alunos a utilizarem o ambiente virtual por meio de situações problemas do cotidiano. Nesta oficina foram utilizadas algumas atividades no formato individual e coletivo, que são descritas na Tabela 2.

Tabela 2 - Atividades trabalhadas em sala de aula no curso de Segurança Web

\begin{tabular}{|c|l|c|}
\hline Atividade & \multicolumn{1}{|c|}{ Descrição } & Formato \\
\hline $\begin{array}{c}\text { Situações de } \\
\text { privacidade: } \\
\text { o que fazer? }\end{array}$ & $\begin{array}{l}\text { Por meio de situações contextualizadas, os participantes } \\
\text { aprendem sobre atitudes do dia-a-dia que impactam na } \\
\text { privacidade tanto da internet como no mundo real. Atividade } \\
\text { Interland: Montanha da Consciência. }\end{array}$ & Individual \\
\hline $\begin{array}{c}\text { Não caia } \\
\text { em } \\
\text { armadilhas }\end{array}$ & $\begin{array}{l}\text { Explicação sobre golpes que ocorrem na internet em redes } \\
\text { sociais e aplicativos de mensagem. Atividade Interland: Rio da } \\
\text { Realidade. }\end{array}$ & Individual \\
\hline $\begin{array}{c}\text { Proteja seus } \\
\text { segredos }\end{array}$ & $\begin{array}{l}\text { Explicação sobre criação de senhas fortes por meio das } \\
\text { diretrizes que constam na apostila. Realiza-se uma dinâmica } \\
\text { intitulada comparação de senhas, onde a turma é dividida em } \\
\text { equipes que escrevem senhas no quadro consideram ser } \\
\text { seguras. Atividade Interland: Torre do Tesouro. }\end{array}$ & Equipe e \\
Individual \\
\hline $\begin{array}{c}\text { É legal ser } \\
\text { gentil }\end{array}$ & $\begin{array}{l}\text { Explicação sobre a importância da gentileza na web. É } \\
\text { importante lembrar que por trás de cada nome de usuário e } \\
\text { avatar há uma pessoa real com sentimentos de verdade. } \\
\text { Atividade Interland: Reino da Bondade. }\end{array}$ & Individual \\
\hline
\end{tabular}

\section{Resultados}

A partir dessas intervenções percebeu-se que os conceitos levados para sala de aula de forma exemplificada e relacionados com o cotidiano das crianças, utilizando uma linguagem simples, trouxe vantagens como facilidade na compreensão do conteúdo por 
VIII Congresso Brasileiro de Informática na Educação (CBIE 2019)

Anais do XXV Workshop de Informática na Escola (WIE 2019)

criar um sentido na vivência do aluno mesmo em conteúdo complexos como criptografia e segurança web.

As atividades plugadas e desplugadas permitiram aos alunos trabalharem conteúdos da computação de forma ativa, sendo algo bastante proveitoso, segundo os próprios alunos e professores da escola de origem que acompanharam as turmas durante as oficinas. Os estudantes compreenderam e exercitaram conceitos vistos em sala de aula de uma maneira diferente e atrativa por lidar com elementos presentes na modernidade, como a tecnologia e suas aplicações no cotidiano.

A respeito da oficina de criptografia foi repensado o ambiente que seriam realizadas as atividades, pois a primeira turma foi levada para um laboratório de informática, algo que os deixou inquietos pela vontade de manipular os computadores, mas não havia a necessidade de tal fato no planejamento da oficina, logo as outras oficinas foram realizadas em sala de aula comum, não impactando no ensino dos conteúdos propostos. Constatou-se com base nas análises iniciais, nas atividades desenvolvidas e na observação de sala de aula que os alunos, em sua maioria, atingiram capacidades plenas para a executar as atividades planejadas e a apropriação do conteúdo.

\section{Conclusões}

Foi possível observar que a adoção de diferentes estratégias nas oficinas, sejam jogos, competição, resolução de problemas ou computação desplugada e plugada, acabam por criar um envolvimento dos alunos no processo de aprendizado, atraindo sua curiosidade. Em sala de aula pode-se trabalhar a desconstrução do ambiente escolar de carteiras enfileiradas, trazendo mais liberdade no decorrer das aulas.

Constatou-se ainda que com o desenvolvimento da proposta a possibilidade de trabalhar conteúdos atitudinais com ensino de computação, tais como trabalho em equipe, esforço e autonomia por parte dos alunos, evidenciando assim a capacidade das aulas de computação contemplarem um número maior de habilidades a serem exploradas e incentivadas por meio da interdisciplinaridade e transdisciplinaridade.

Sendo assim é possível ensinar de forma desplugada, em laboratórios ou com outras metodologias ativas que possam existir, de forma que as habilidades a serem trabalhadas fiquem mais próximas das realidades dos alunos. Espera-se que com este trabalho ocorra uma presença mais efetiva do ensino da computação no ensino fundamental, mesmo diante dos obstáculos que a educação pública brasileira enfrenta.

\section{Referências}

BORDINI et al. Computação na educação básica no Brasil: estado da arte. Rev. Inform. Teor. Apl. (Online), Porto Alegre, v. 23, n. 2, p. 210-238, novembro/2016.

CASTRO, C. S.; VILARIM, G. de O. Licenciatura em Computação no cenário nacional: embates, institucionalização e o nascimento de um novo curso. Revista Espaço Acadêmico, n. 148, set/2013. 